Fission Product Gamma-Ray Line Pairs Sensitive to Fissile Material and Neutron Energy

R. E. Marrs, E. B. Norman, J. T. Burke, R. A. Macri, H. A. Shugart, E. Browne, A. R. Smith

November 27, 2007

Nuclear Instruments and Methods in Physics Research A 
This document was prepared as an account of work sponsored by an agency of the United States government. Neither the United States government nor Lawrence Livermore National Security, LLC, nor any of their employees makes any warranty, expressed or implied, or assumes any legal liability or responsibility for the accuracy, completeness, or usefulness of any information, apparatus, product, or process disclosed, or represents that its use would not infringe privately owned rights. Reference herein to any specific commercial product, process, or service by trade name, trademark, manufacturer, or otherwise does not necessarily constitute or imply its endorsement, recommendation, or favoring by the United States government or Lawrence Livermore National Security, LLC. The views and opinions of authors expressed herein do not necessarily state or reflect those of the United States government or Lawrence Livermore National Security, LLC, and shall not be used for advertising or product endorsement purposes. 


\title{
Fission Product Gamma-Ray Line Pairs Sensitive to Fissile Material and Neutron Energy
}

\author{
R. E. Marrs ${ }^{\mathrm{a}, *}$, E. B. Norman ${ }^{\mathrm{a}, \mathrm{b}}$, J. T. Burke ${ }^{\mathrm{a}}$, R. A. Macri ${ }^{\mathrm{a}}$, H. A. Shugart ${ }^{\mathrm{c}}$, E. Browne $^{\mathrm{d}}$, \\ and A. R. Smith \\ ${ }^{a}$ Lawrence Livermore National Laboratory, Livermore, CA 94551, USA \\ ${ }^{\mathrm{b}}$ Department of Nuclear Engineering, University of California, Berkeley, CA 94720, USA \\ ${ }^{\mathrm{c}}$ Department of Physics, University of California, Berkeley, CA 94720, USA \\ ${ }^{\mathrm{d}}$ Lawrence Berkeley National Laboratory, Berkeley, CA 94720, USA
}

\begin{abstract}
The beta-delayed gamma-ray spectra from the fission of ${ }^{235} \mathrm{U},{ }^{238} \mathrm{U}$, and ${ }^{239} \mathrm{Pu}$ by thermal and near-14-MeV neutrons have been measured for delay times ranging from 1 minute to 14 hours. Spectra at all delay times contain sets of prominent gamma-ray lines with intensity ratios that identify the fissile material and distinguish between fission induced by low-energy or high-energy neutrons.
\end{abstract}

\section{Introduction}

Nuclear fission produces a complex spectrum of beta-delayed gamma rays from decay of the many different fission products. In spite of the complexity, differences in the fission product gamma-ray emission spectra for different fissionable isotopes allow the identification of the fissionable material without chemical separation of the fission products. Other differences in the spectra provide information about the incident neutron energy.

Previous work in this area has focused on the detection of hidden fissile material [1] or the isotopic composition of fissionable samples [2,3]. In both cases, the irradiation time (by neutrons or gamma-rays), the delay time, and the counting time can be

* Corresponding author. Tel.: +1-925-422-3890; E-mail: marrs1@1lnl.gov 
controlled. Sudden, possibly unexpected fission events such as a nuclear explosion, a pulsed reactor, or the exposure of fissile material to a burst of neutrons produce an immediate source of fission product gamma rays. Gamma-ray spectroscopy following these events can determine the amount of fission from different fissionable isotopes and information about the energy spectrum of the neutrons that induced fission, but this requires appropriate sets of diagnostic gamma-ray lines that span a broad range of delay times at which spectra might be obtained.

We have measured time-dependent fission product gamma-ray spectra from roughly 1 minute to 14 hours after a single exposure of fissile samples to a neutron beam. Here we report the identification of gamma-ray line pairs and groups that are prominent at different times in the gamma-ray spectrum from unseparated fission products, and are sensitive to the fissile material or, separately, the incident neutron energy.

\section{Experimental Method}

Samples of $0.19 \mathrm{~g}{ }^{235} \mathrm{U}, 7.74 \mathrm{~g}{ }^{238} \mathrm{U}$, and $0.57 \mathrm{~g}{ }^{239} \mathrm{Pu}$ were irradiated with neutrons produced from a deuteron beam incident on a thick beryllium target at the 88inch cyclotron at Lawrence Berkeley National Laboratory. For one set of measurements a $16-\mathrm{MeV}, 3.3-\mu \mathrm{A}$ deuteron beam was used to produce neutrons which were thermalized in steel and polyethylene surrounding the beryllium production target. For a second set of measurements a $33-\mathrm{MeV}, 1.0-\mu \mathrm{A}$ deuteron beam was used to produce a neutron energy distribution centered at $14 \mathrm{MeV}$, the steel and polyethylene were removed, and the fissionable samples were placed immediately behind the beryllium neutronproduction target. For the 14-MeV irradiations, the samples were covered with $1 \mathrm{~mm}$ of cadmium to exclude thermal neutrons.

Each sample was exposed to neutrons for 5 minutes for thermal neutrons and 1 minute for $14-\mathrm{MeV}$ neutrons. Approximately $10^{8}$ fissions were produced in each sample. The samples were removed immediately after exposure and counted with germanium gamma-ray detectors for a long sequence of time intervals beginning approximately 1 
minute after the end of neutron irradiation. Polyethylene $(2.5 \mathrm{~cm}$ thick) of and lead $(3.2$ mm thick) were placed between each sample and detector to absorb beta-decay electrons and attenuate low-energy gamma rays. The energy-dependent efficiency for each of the gamma-ray detectors (with the polyethylene and lead absorbers) was determined with standard calibrated sources. The measured gamma-ray intensity ratios were corrected for detector efficiency variation. One line ratio required a $4 \%$ correction, and all of the other corrections were less than 2\%. Gamma-ray spectra were recorded from each of the samples before irradiation in order to identify background lines from the natural radioactivity present in the samples.

\section{Neutron Energy Distribution}

Gold-foil activation measurements showed that the thermal neutron flux was at least 100 -fold greater than the fast neutron flux for the thermal neutron measurements. In addition, the thermal-neutron fission cross sections for ${ }^{235} \mathrm{U}$ and ${ }^{239} \mathrm{Pu}$ are roughly 500 times greater than the fast-neutron fission cross sections. Hence fast-neutron fission made a negligible contribution to the thermal-neutron data.

Previous measurements of neutron energy spectra for deuteron beams of various energies on thick targets imply that a deuteron energy of 33-MeV produces a broad neutron energy distribution centered at roughly $14 \mathrm{MeV}$ [4-6]. This was corroborated by activation measurements of foils at our sample location that have different activation thresholds.

\section{Time Bins}

Following irradiation, spectra were recorded for ten 1-minute time bins, followed by fifteen 3-minute time bins, followed by a variable number of 10 -minute time bins. This enabled the observation of all significant spectral changes with time scales ranging from minutes to a few days. To simplify the analysis and reporting of the measurements, we combined the experimental data into six larger time bins: $5-8 \mathrm{~m}, 18-33 \mathrm{~m}, 1-1.5$ 
h, $2.5-3.5 \mathrm{~h}, 5-7 \mathrm{~h}$, and $10-14 \mathrm{~h}$ after fission as measured from the midpoint of the irradiation period. These time bins are long enough to obtain good statistical precision, and they span the full time range of our data set. Most importantly, examination of the complete data set confirms that these time bins capture all of the time-dependent features in the fission-product spectra so that our selection of diagnostic gamma-ray lines leaves no gaps in temporal coverage. In what follows, we report experimental line ratios for these six time intervals; however a different choice of time intervals would yield similar results and the same conclusions. The actual starting times for the counting intervals differed by up to $9 \%$ from the nominal values due to variations in transporting the samples. Small corrections were made for these variations as described below.

\section{Line Pair Selection}

We examined the fission product gamma-ray spectra at various times after fission and identified sets of prominent lines with diagnostic value. We selected line pairs and multiplets with intensity ratios that differ significantly between ${ }^{235} \mathrm{U}$ and ${ }^{239} \mathrm{Pu}$ fission but are relatively insensitive to neutron energy. Conversely, we selected other line pairs that are very sensitive to neutron energy but relatively insensitive to the fissioning isotope. Distinguishing between ${ }^{238} \mathrm{U}$ and ${ }^{239} \mathrm{Pu}$ fission is difficult because the fission product distributions are very similar for neutron-induced fission. We identified only two gamma-ray lines (both from ${ }^{132} \mathrm{I}$ decay) with a large intensity difference between ${ }^{238} \mathrm{U}$ and ${ }^{239} \mathrm{Pu}$. Since ${ }^{238} \mathrm{U}$ is not fissionable by thermal neutrons, we measured its fission product gamma-ray spectrum only at $14 \mathrm{MeV}$.

All of the selected gamma-ray lines meet several requirements. The contribution of unresolved lines to the observed intensity of the selected lines is either insignificant or small and easily corrected for. (The exception is a few cases for which a doublet of two strong unresolved lines was intentionally selected as the primary "line.") Each of the selected gamma-ray lines was validated by searching the Table of Radioactive Isotopes [7] for other lines of similar energy, by comparing the measured intensity and decay rate to data-base values, and (where possible) by comparing the measured intensity to that of 
other lines from the same isotope. Background levels and the presence of significant unresolved lines preclude the use of some gamma-ray lines that would otherwise be favorable based on their sensitivity to fissile material or neutron energy. Line pairs were also selected to be close in energy in order to minimize the energy-dependent corrections for absorption and detector efficiency in an actual diagnostic measurement. Gamma rays below $500-\mathrm{keV}$ energy were avoided because of the complexity of the spectra and high background levels at lower energies.

\section{Fissile Material Identification}

${ }^{235} U-{ }^{239} \mathrm{Pu}$ Fission Split

Yields of fission products near mass number 90 differ significantly for ${ }^{235} \mathrm{U}$ and

${ }^{239} \mathrm{Pu}$ fission, and they are relatively insensitive to neutron energy. When compared to gamma rays from other mass chains, several gamma-ray lines from these fission products or their daughters provide identification of the fissile material. For mixed materials, these line ratios provide a measure of the fission split between ${ }^{235} \mathrm{U}$ and ${ }^{239} \mathrm{Pu}$.

Table I lists gamma-ray line pairs or multiplets that we have identified as sensitive to fissile material for the different time ranges studied here. Although there are other lines that could have been included, the selected lines are of good quality and span the full time range of interest. The measured spectra contain many gamma-ray lines that are relatively insensitive to fissionable isotope and could be used to form ratios with the isotope-sensitive lines. We have selected a few of these lines that are particularly attractive for inclusion in Table I. For all of the lines listed in Table I, we searched the Table of Radioactive Isotopes [7] for other lines that might be unresolved and unrecognized in our measured spectra - we found none that would make a significant contribution for the time intervals listed in Table I. 
Table I. Gamma-ray line pairs and multiplets that are sensitive to fissile material. Gamma rays are identified by parent isotope and energy (keV), and are grouped by energy band and time bin. The ratio of the intensity of a gamma ray above the dashed line to that of a gamma ray below the dashed line in each group is larger in ${ }^{235} \mathrm{U}$ fission than in ${ }^{239} \mathrm{Pu}$ fission.

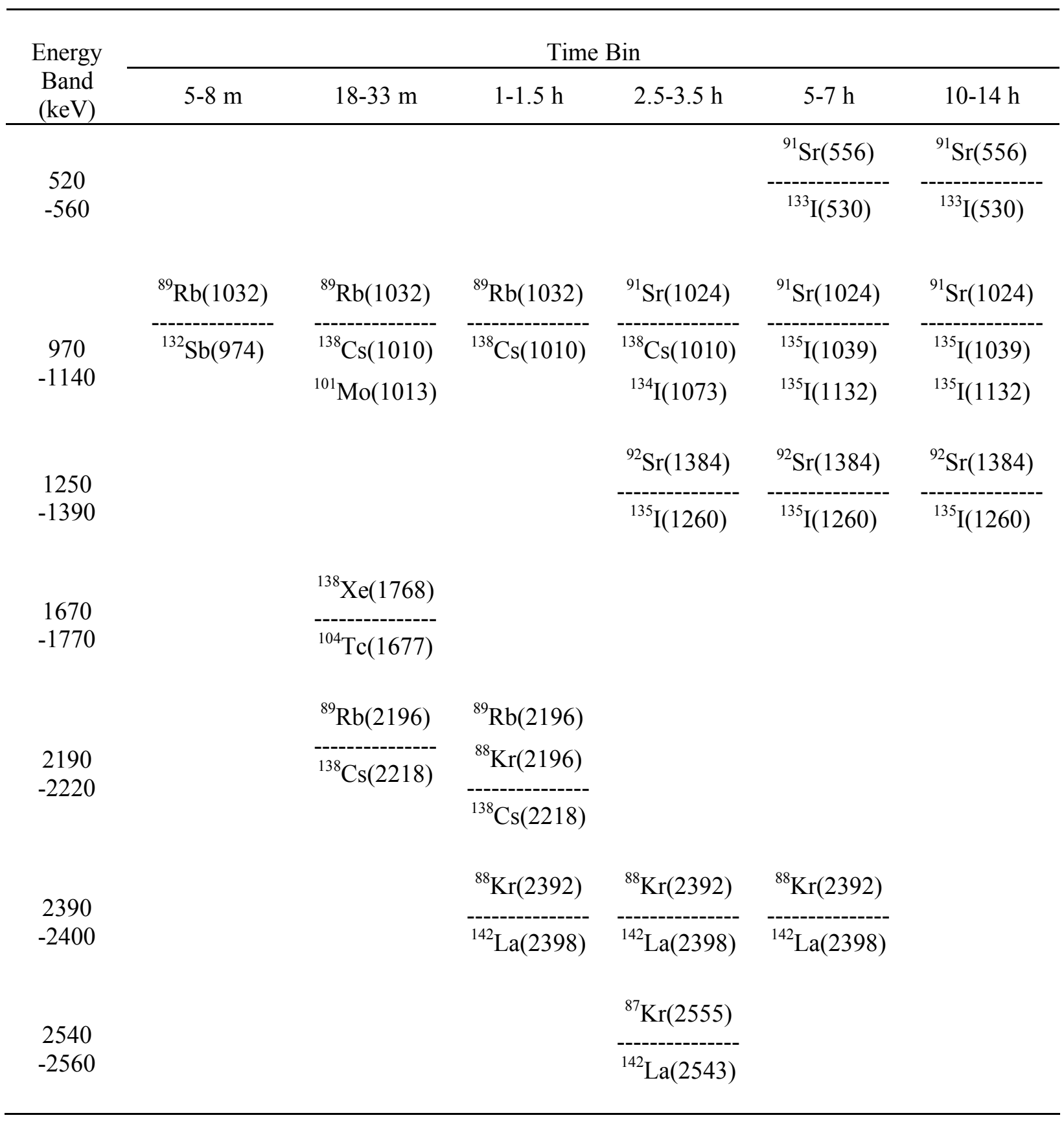


From the gamma-ray lines listed in Table I we selected one line pair from each time bin for more detailed analysis. Plots of spectral segments containing these lines are shown in Fig. 1. Spectra for thermal neutron fission of both ${ }^{235} \mathrm{U}$ and ${ }^{239} \mathrm{Pu}$ are shown. Decay of the fission products and their daughters causes the intensity of each gamma ray to vary with time so that different gamma-ray lines are prominent at different times after fission. This is illustrated in Fig. 2, which plots the expected time dependence of the gamma-ray lines identified in Fig. 1. The ratio of the intensity of either of the isotopesensitive lines, ${ }^{89} \mathrm{Rb}(1032)$ or ${ }^{91} \mathrm{Sr}(1024)$, to the intensity of one of the reference lines provides a measure of the fission split between ${ }^{235} \mathrm{U}$ and ${ }^{239} \mathrm{Pu}$. The ${ }^{132} \mathrm{Sb}(974)$ and ${ }^{138} \mathrm{Cs}(1010)$ lines contain contributions from both the ground and metastable states of these isotopes, and both the ground and metastable state were included in the calculated time dependence.

The expected time-dependent intensity of each of the selected gamma-ray lines was calculated by numerical integration using the independent fission-product yields tabulated by England and Rider [8] in combination with the half lives [7] and gamma-ray branching ratios [7]. We refer to these as the "theoretical" intensities. They were integrated over the selected time intervals for comparison to our measurements. The measured gamma-ray intensities were obtained from least-squares fits to the timeintegrated spectra. They are used in the present work only as intensity ratios. Hence absolute intensity measurements were not required. 

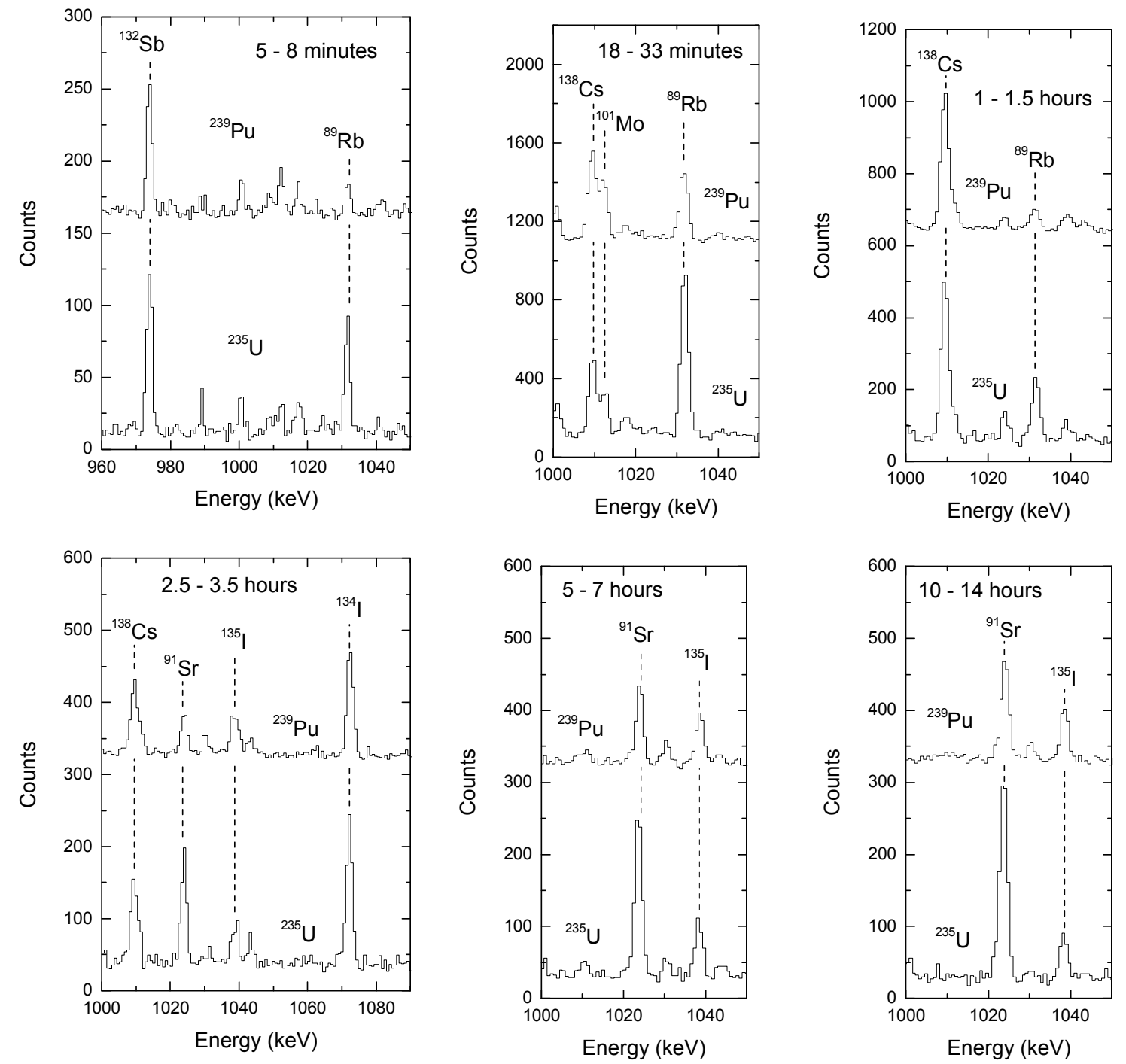

Fig. 1. Spectral regions near $1000 \mathrm{keV}$ for each of the time bins showing line pairs that are sensitive to fissile material $\left({ }^{235} \mathrm{U}\right.$ or $\left.{ }^{239} \mathrm{Pu}\right)$. All spectra are for fission induced by thermal neutrons. The vertical scales apply to the ${ }^{235} \mathrm{U}$ spectra. The ${ }^{239} \mathrm{Pu}$ spectra have been multiplied by a scale factor and offset vertically for display purposes. 

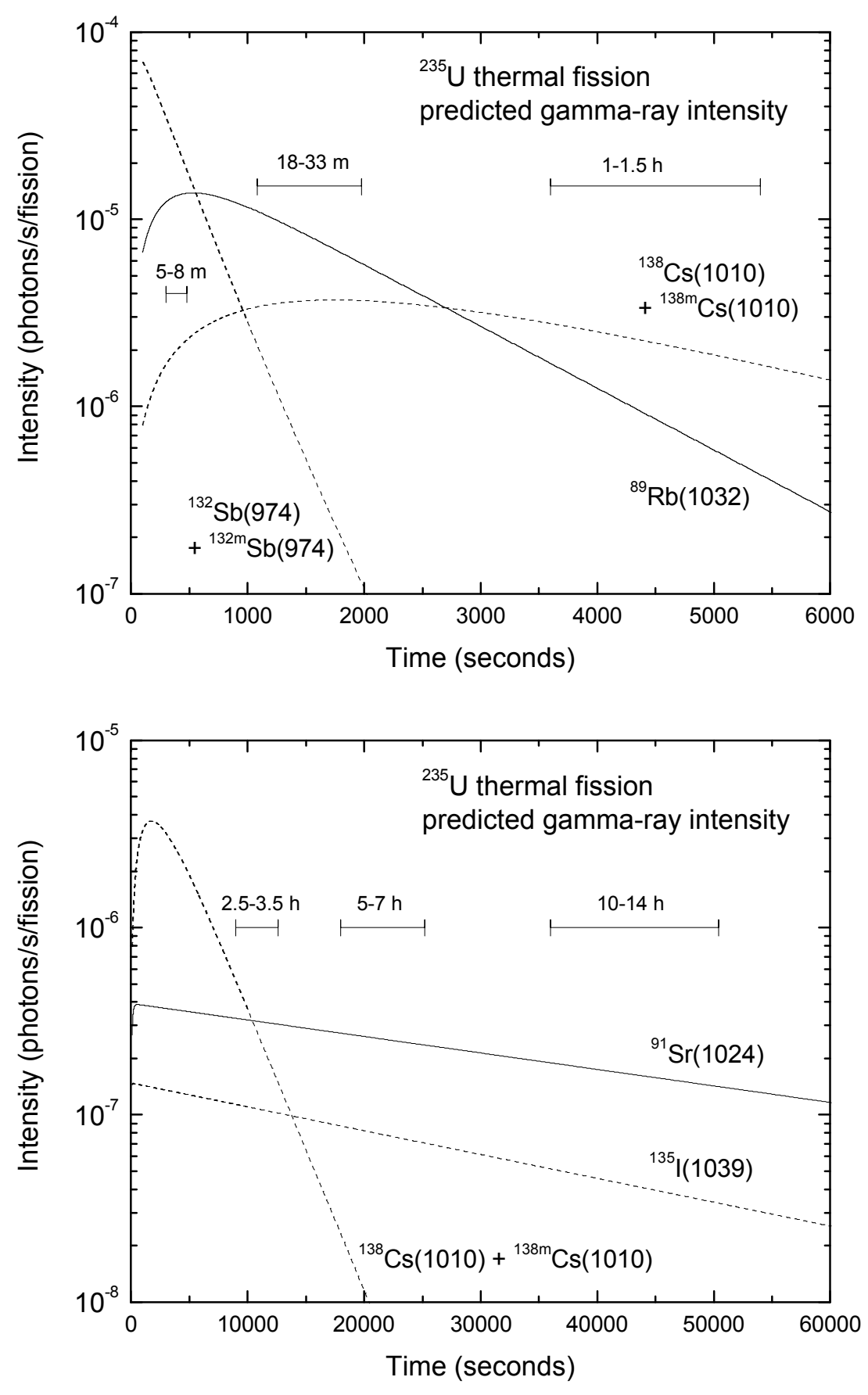

Fig. 2. Theoretical time dependence of the indicated gamma-ray intensities for thermalneutron fission of ${ }^{235} \mathrm{U}$. Gamma rays that are more intense in ${ }^{235} \mathrm{U}$ fission than ${ }^{239} \mathrm{Pu}$ fission are shown as solid curves. Reference gamma rays are shown as dashed curves. Bars indicate the times bins used for integration. Top: early time. Bottom: late time. 
As can be appreciated from Fig. 1, identification of a fission event as either pure ${ }^{235} \mathrm{U}$ or pure ${ }^{239} \mathrm{Pu}$ would be obvious from visual comparison of relative gamma-ray intensities such as those shown. However an accurate determination of the ${ }^{235} \mathrm{U}-{ }^{239} \mathrm{Pu}$ fission split for a mixed source requires a more careful treatment of weak incompletely resolved background lines. We examined the tabulated data for possible unresolved lines, calculated the decay curves for lines of concern, identified contributions of more than $5 \%$ of the primary line intensity in each time bin of interest, and made corrections as described below. The time-dependent contributions of the two most important incompletely resolved lines near the ${ }^{138} \mathrm{Cs}(1010)$ line are plotted in Fig. 3. and illustrate the time varying contribution of background lines. Because of the spacing of the ${ }^{138} \mathrm{Cs}$, ${ }^{142} \mathrm{La}$, and ${ }^{101} \mathrm{Mo}$ lines near $1010 \mathrm{keV}$, these lines were fitted as three separate peaks in our spectra.

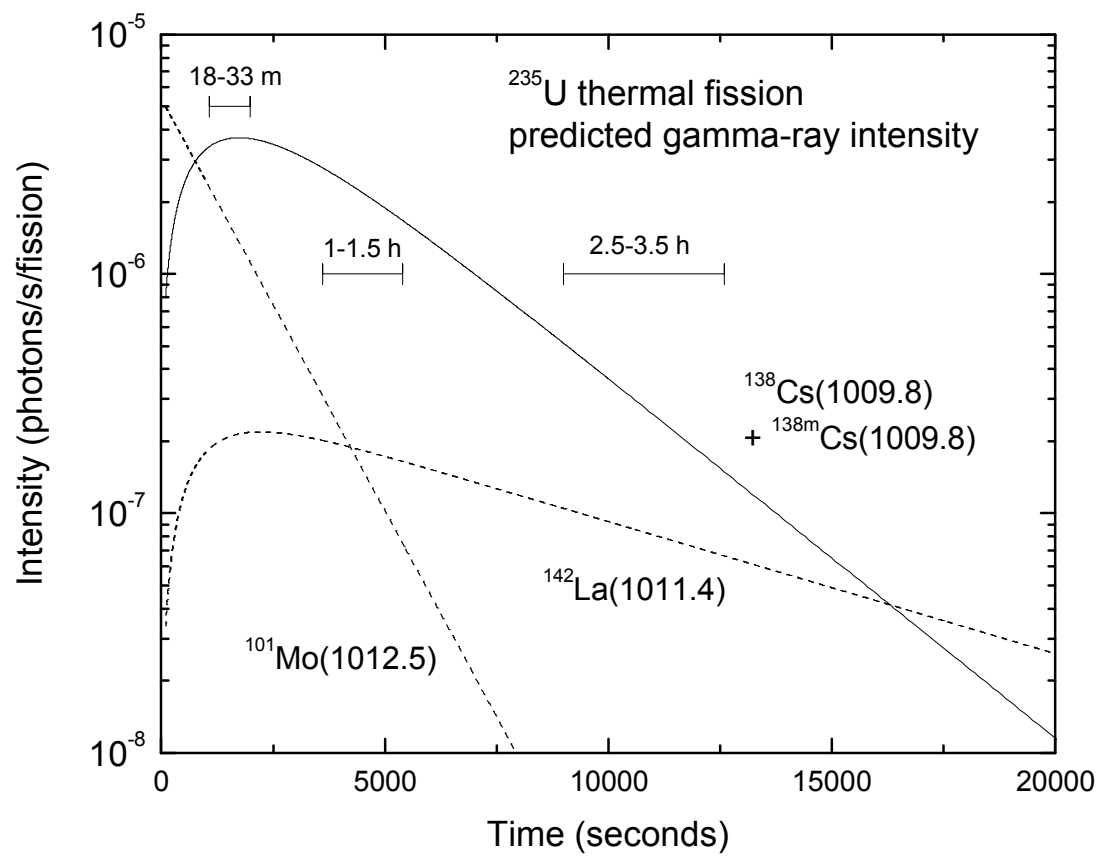

Fig. 3. Time dependence of incompletely resolved gamma-ray lines near $1010 \mathrm{keV}$.

All of the selected gamma rays yielded good quality peak fits consistent with the absence of unrecognized lines. As a further check for the presence of unresolved and 
unrecognized lines, we fitted all of the peaks for which measured intensity ratios are reported over multiple shorter time intervals and compared the observed decay rate to the theoretical time dependence. We also compared the measured peak intensities to those of other lines from the same isotope where possible and obtained relative intensities consistent with tabulated gamma-ray intensities [7].

Measured line ratios for both thermal-neutron and 14-MeV-neutron fission are compared to the theoretical values in Table II. In all cases there is good agreement between the measured and theoretical line ratios. As can be seen, the line ratios are less sensitive to neutron energy than fissile isotope and allow identification of the fissile material as ${ }^{235} \mathrm{U}$ or ${ }^{239} \mathrm{Pu}$ even with no information about the neutron energy spectrum. (The one exception is the ${ }^{89} \mathrm{Rb}(1032) /{ }^{132} \mathrm{Sb}(974)$ ratio for ${ }^{239} \mathrm{Pu}$ fission in the 5-8 $\mathrm{m}$ time bin, which increases by a factor of 2.6 from thermal to $14-\mathrm{MeV}$ neutron energy and is nearly the same as the ${ }^{235} \mathrm{U}$ value at $14 \mathrm{MeV}$.) For the case of a mixture of ${ }^{235} \mathrm{U}$ and ${ }^{239} \mathrm{Pu}$ fission and an unknown neutron energy spectrum, the accuracy of the measured fission split can be improved with corrections based on the fraction of high energy neutrons as determined from energy-sensitive line pairs. The theoretical gamma-ray line ratios for fission-spectrum neutrons are also included in Table II. We did not obtain data for fission-spectrum neutrons, however the theoretical line ratios are so close to those for thermal neutrons that the difference can be neglected for the purpose of identifying fissile material.

Although we did not obtain data beyond 14 hours, the ${ }^{91} \operatorname{Sr}(1024) /{ }^{135} \mathrm{I}(1039)$ line ratio will clearly be useful well beyond that time because of the persistence of these lines. These lines may be the most valuable because of the long time interval during which they are prominent, the absence of significant background lines, and their sensitivity to fissionable isotope. 
Table II. Intensity ratios in the 970-1140 keV energy band for each time bin. One ratio is shown for each time bin. Measured values for both thermal and 14-MeV neutron fission are compared to the theoretical values. Values for ${ }^{235} \mathrm{U}$ and ${ }^{239} \mathrm{Pu}$ are shown in the first and second rows, respectively, in each time bin.

\begin{tabular}{|c|c|c|c|c|c|c|c|}
\hline \multirow{4}{*}{$\begin{array}{l}\text { Time } \\
\text { Bin } \\
5-8 \mathrm{~m}\end{array}$} & \multirow{4}{*}{$\begin{array}{c}\begin{array}{c}\text { Line } \\
\text { Pair }\end{array} \\
\frac{{ }^{89} \mathrm{Rb}(1032)}{{ }^{132} \mathrm{Sb}(974)}\end{array}$} & \multicolumn{6}{|c|}{ Intensity Ratio } \\
\hline & & \multirow{2}{*}{$\begin{array}{c}\begin{array}{c}\text { Thermal } \\
\text { Expt }\end{array} \\
0.66 \pm 0.07\end{array}$} & \multirow{2}{*}{$\begin{array}{c}\text { Thermal } \\
\text { Theory } \\
0.522\end{array}$} & \multirow{2}{*}{$\begin{array}{c}\text { Fission } \\
\text { Spectrum } \\
\text { Theory }\end{array}$} & \multirow{2}{*}{$\begin{array}{c}\begin{array}{c}14-\mathrm{MeV} \\
\text { Expt }\end{array} \\
0.74 \pm 0.14\end{array}$} & \multicolumn{2}{|c|}{$\begin{array}{c}\text { 14-MeV } \\
\text { Theory }\end{array}$} \\
\hline & & & & & & 0.839 & ${ }^{235} \mathrm{U}$ \\
\hline & & $0.28 \pm 0.05$ & 0.188 & 0.255 & $0.73 \pm 0.15$ & 0.726 & ${ }^{239} \mathrm{Pu}$ \\
\hline \multirow{2}{*}{$18-33 \mathrm{~m}$} & ${ }^{89} \mathrm{Rb}(1032)$ & $2.30 \pm 0.14$ & 2.25 & 2.08 & $2.72 \pm 0.15$ & 2.86 & ${ }^{235} \mathrm{U}$ \\
\hline & ${ }^{138} \mathrm{Cs}(1010)$ & $0.87 \pm 0.04$ & 0.876 & 0.887 & $1.43 \pm 0.05$ & 1.62 & ${ }^{239} \mathrm{Pu}$ \\
\hline \multirow{2}{*}{$1-1.5 \mathrm{~h}$} & ${ }^{89} \mathrm{Rb}(1032)$ & $0.43 \pm 0.03$ & 0.419 & 0.393 & $0.51 \pm 0.05$ & 0.591 & ${ }^{235} \mathrm{U}$ \\
\hline & ${ }^{138} \mathrm{Cs}(1010)$ & $0.17 \pm 0.02$ & 0.169 & 0.177 & $0.22 \pm 0.02$ & 0.378 & ${ }^{239} \mathrm{Pu}$ \\
\hline \multirow{2}{*}{$2.5-3.5 \mathrm{~h}$} & ${ }^{91} \mathrm{Sr}(1024)$ & $1.15 \pm 0.14$ & 1.09 & 1.07 & $1.28 \pm 0.14$ & 1.48 & ${ }^{235} \mathrm{U}$ \\
\hline & ${ }^{138} \mathrm{Cs}(1010)$ & $0.37 \pm 0.05$ & 0.521 & 0.547 & $0.75 \pm 0.05$ & 0.911 & ${ }^{239} \mathrm{Pu}$ \\
\hline \multirow[b]{2}{*}{$5-7 \mathrm{~h}$} & ${ }^{91} \mathrm{Sr}(1024)$ & $3.21 \pm 0.46$ & 3.23 & 3.15 & $3.38 \pm 0.41$ & 3.97 & ${ }^{235} \mathrm{U}$ \\
\hline & $\frac{}{{ }^{135} \mathrm{I}(1039)}$ & $1.59 \pm 0.16$ & 1.31 & 1.43 & $2.22 \pm 0.14$ & 1.95 & ${ }^{239} \mathrm{Pu}$ \\
\hline \multirow{2}{*}{$10-14 \mathrm{~h}$} & ${ }^{91} \mathrm{Sr}(1024)$ & $4.71 \pm 0.67$ & 3.91 & 3.82 & No & 4.81 & ${ }^{235} \mathrm{U}$ \\
\hline & ${ }^{135} \mathrm{I}(1039)$ & $1.74 \pm 0.13$ & 1.59 & 1.74 & Data & 2.36 & ${ }^{239} \mathrm{Pu}$ \\
\hline
\end{tabular}

The values for the measured line ratios have been adjusted to the nominal time intervals and corrected for buildup and decay during the irradiation interval using the tabulated independent yields and decay rates of the isotopes in each mass chain. This allows the measured line ratios to be directly compared to the theoretical values. Most of the adjustments are less than $1 \%$ and the largest is $24 \%$. The theoretical contributions of 
possible unresolved lines were calculated in the same manner as the theoretical intensity of the primary lines. The measured peak intensities were then corrected for any (theoretical) unresolved-line contributions greater than 5\%. The largest correction was for the ${ }^{89} \mathrm{Rb}$ (1032) line from ${ }^{239} \mathrm{Pu}$ fission in the $1-1.5 \mathrm{~h}$ time bin, where a correction of $17 \%$ was applied for thermal neutrons and 25\% for $14-\mathrm{MeV}$ neutrons. Most of the other peaks required no correction for unresolved lines. The cumulative yield of some fission products is affected by beta-delayed neutron emission. However, based on the tabulated independent yields [8] and radioactive decay data [7], the net effect of beta-delayed neutron emission on the intensity of all of the gamma-ray lines studied in the present work is less than $10 \%$ and has been neglected. The listed experimental uncertainties are the statistical errors from the least-squares fitting of the gamma-ray peaks.

\section{${ }^{238}$ U Fission}

Fission of ${ }^{238} \mathrm{U}$ is difficult to distinguish from ${ }^{239} \mathrm{Pu}$ fission because the mass distributions of the fission products are very similar for neutron-induced fission. Since ${ }^{238} \mathrm{U}$ is not fissionable by thermal neutrons, we measured ${ }^{238} \mathrm{U}$ fission product gamma-ray spectra only for 14-MeV neutrons. We identified two prominent gamma-ray lines, ${ }^{132} \mathrm{I}(668)$ and ${ }^{132} \mathrm{I}(773)$, whose intensities are markedly different for ${ }^{238} \mathrm{U}$ and ${ }^{239} \mathrm{Pu}$ (or ${ }^{235} \mathrm{U}$ ) fission. Selected reference gamma-ray lines are listed with the ${ }^{132} \mathrm{I}$ lines in Table III along with the time intervals for which the intensity ratios are useful. 
Table III. Gamma-ray lines that distinguish between ${ }^{238} \mathrm{U}$ and ${ }^{239} \mathrm{Pu}$ fission. Gamma rays are identified by parent isotope and energy $(\mathrm{keV})$, and are grouped by energy band and time bin. The ${ }^{132} \mathrm{I}$ gamma rays are much stronger for ${ }^{239} \mathrm{Pu}$ than ${ }^{238} \mathrm{U}$ fission relative to the gamma rays listed below the dashed lines.

\begin{tabular}{cccc}
\hline \multirow{3}{*}{$\begin{array}{c}\text { Energy } \\
\text { Band } \\
(\mathrm{keV})\end{array}$} & $1-1.5 \mathrm{~h}$ & $2.5-3.5 \mathrm{~h}$ & $5-7 \mathrm{~h}$ \\
\cline { 2 - 4 } & ${ }^{132} \mathrm{I}(668)$ & ${ }^{132} \mathrm{I}(668)$ & ${ }^{132} \mathrm{I}(668)$ \\
& $----{ }^{142} \mathrm{La}(641)$ & ${ }^{142} \mathrm{La}(641)$ & ${ }^{142} \mathrm{La}(641)$ \\
640 & ${ }^{134} \mathrm{I}(677)$ & ${ }^{97} \mathrm{Nb}(658)$ & ${ }^{97} \mathrm{Nb}(658)$ \\
-680 & & ${ }^{134} \mathrm{I}(677)$ & \\
& & & \\
& & & \\
760 & ${ }^{132} \mathrm{I}(773)$ & ${ }^{132} \mathrm{I}(773)$ \\
-850 & ${ }^{134} \mathrm{Te}(767)$ & ${ }^{134} \mathrm{Te}(767)$ & ${ }^{134} \mathrm{Te}(767)$ \\
& ${ }^{134} \mathrm{I}(767)$ & ${ }^{134} \mathrm{I}(767)$ & ${ }^{134} \mathrm{I}(767)$ \\
& & ${ }^{134} \mathrm{I}(847)$ & ${ }^{134} \mathrm{I}(847)$ \\
\hline
\end{tabular}

As illustrated in Fig. 4, unresolved gamma-ray lines from ${ }^{134} \mathrm{Te}$ and ${ }^{134} \mathrm{I}$ at 767 $\mathrm{keV}$ provide good reference lines for comparison to the ${ }^{132} \mathrm{I}(773)$ line. The ${ }^{134} \mathrm{I}(847)$ line is stronger than the blended ${ }^{134} \mathrm{Te}(767)$ and ${ }^{134} \mathrm{I}(767)$ lines at all times, but it is farther away in energy from the ${ }^{132} \mathrm{I}(773)$ line. Hence it is more sensitive to differential absorption and variation in detector efficiency. Nearby lines from ${ }^{142} \mathrm{La}(641),{ }^{97} \mathrm{Nb}(658)$, and ${ }^{134} \mathrm{I}(677)$ provide good reference lines for the ${ }^{132} \mathrm{I}(668)$ line. We did not obtain experimental values for ${ }^{132} \mathrm{I}(668)$ line ratios because of strong adjacent lines from natural radioactivity in the ${ }^{239} \mathrm{Pu}$ sample. An incompletely resolved gamma-ray line from plutonium radioactivity also appears near the ${ }^{132} \mathrm{I}(773)$ line in our spectra (see Fig. 4). We removed the contribution of this gamma ray by subtracting the pre-irradiation spectrum of the plutonium sample acquired with the same detector. The normalization 
factor for the subtraction was determined from the strong 413-keV plutonium gammaray.

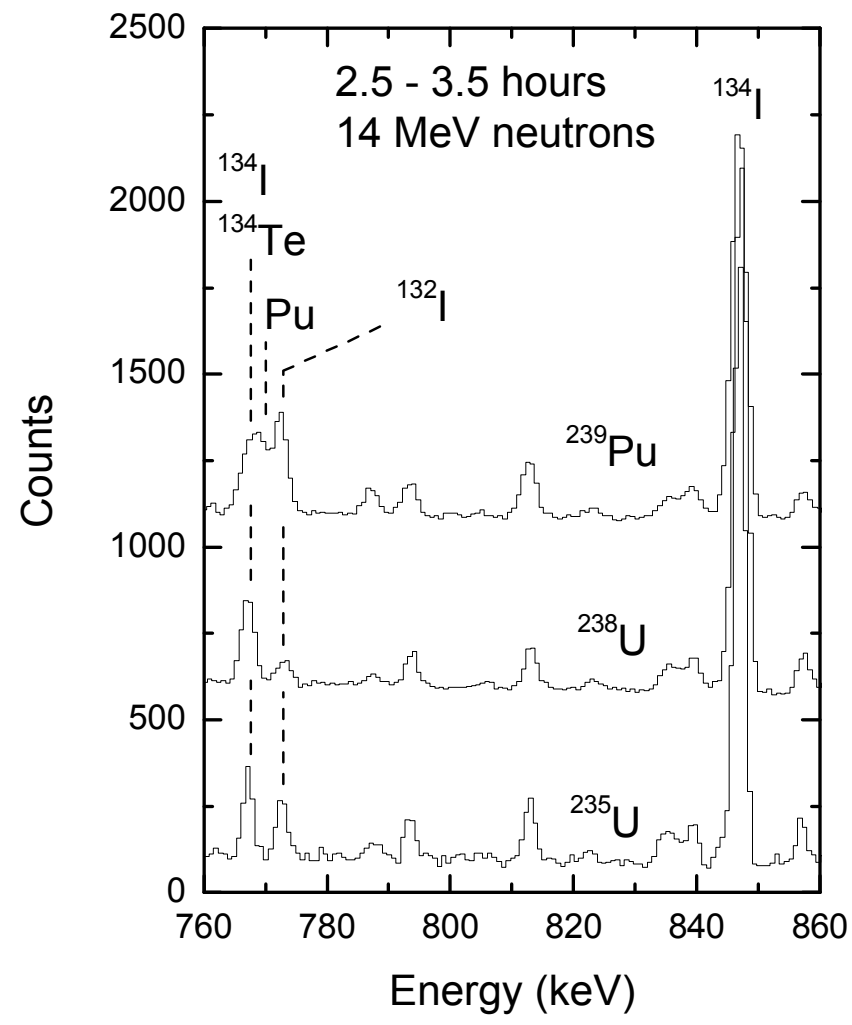

Fig. 4. Comparison of gamma-ray spectra from ${ }^{235} \mathrm{U},{ }^{238} \mathrm{U}$, and ${ }^{239} \mathrm{Pu}$ fission by $14-\mathrm{MeV}$ neutrons, integrated from 2.5 to 3.5 hours after fission. The unresolved line labeled $\mathrm{Pu}$ is from natural radioactivity of the ${ }^{239} \mathrm{Pu}$ sample and is not produced by fission. The vertical scale applies to the ${ }^{235} \mathrm{U}$ spectrum. The ${ }^{238} \mathrm{U}$ and ${ }^{239} \mathrm{Pu}$ spectra have been multiplied by scale factors and offset vertically for display purposes. Unresolved lines from ${ }^{134} \mathrm{I}$ and ${ }^{134} \mathrm{Te}$ both contribute to the peak at $767 \mathrm{keV}$.

The different intensity of the ${ }^{132} \mathrm{I}$ gamma rays for ${ }^{238} \mathrm{U}$ vs. ${ }^{239} \mathrm{Pu}$ fission arises from a difference in the independent yields of the mass-132 isotopes rather than the cumulative yield for the whole mass chain. This, and the different lifetimes of the mass-132 isotopes leads to a different time dependence for the ${ }^{132} \mathrm{I}$ gamma rays following ${ }^{238} \mathrm{U}$ and ${ }^{239} \mathrm{Pu}$ 
fission as shown in Fig. 5. The intensities of the ${ }^{132} \mathrm{I}(773)$ gamma-ray and the $767-\mathrm{keV}$ reference gamma rays from mass-134 isotopes have an opposite dependence on fissionable isotope, which enhances the isotope sensitivity of their ratio. However the ${ }^{132}$ I gamma ray loses its isotope sensitivity after roughly 12 hours if the theoretical predictions are correct.

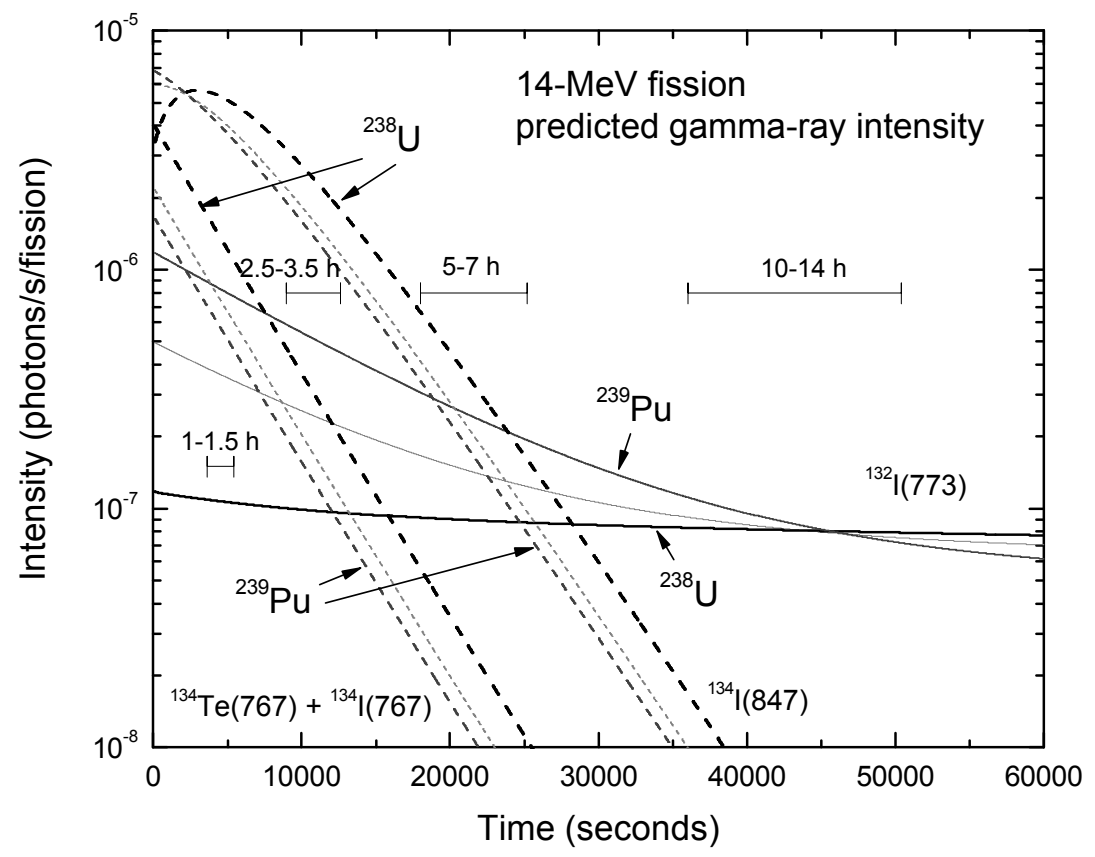

Fig. 5. Theoretical time dependence of the gamma-ray intensities for ${ }^{132} \mathrm{I}(773)$, ${ }^{134} \mathrm{Te}(767)+{ }^{134} \mathrm{I}(767)$, and ${ }^{134} \mathrm{I}(847)$ following fission by $14-\mathrm{MeV}$ neutrons. Decay curves are shown for ${ }^{238} \mathrm{U},{ }^{239} \mathrm{Pu}$, and ${ }^{235} \mathrm{U}$ (unlabeled).

Gamma-ray intensity ratios for 14-MeV neutron fission are listed in Tables IV and $\mathrm{V}$ for the time intervals for which they are useful. At shorter and longer times the line ratios are not a useful diagnostic because at least one of the lines is too weak. Spectra for ${ }^{238} \mathrm{U}$ fission were not recorded beyond roughly 4 hours, so we did not search for diagnostic lines at times later than that. The observed 5- to 10-fold difference in the line ratios for ${ }^{238} \mathrm{U}$ and ${ }^{239} \mathrm{Pu}$ fission is consistent with the theoretical values, although the 
theoretical ratios are systematically larger than the measured ratios. The broad neutron energy distribution in our experiment may contribute to the difference between measurement and theory (see discussion below under neutron energy).

Table IV. Intensity ratios for ${ }^{132} \mathrm{I}(773) /\left[{ }^{134} \mathrm{Te}(767)+{ }^{134} \mathrm{I}(767)\right]$. Measured values for 14-MeV neutron fission are compared to the theoretical values for ${ }^{238} \mathrm{U},{ }^{235} \mathrm{U}$, and ${ }^{239} \mathrm{Pu}$.

\begin{tabular}{|c|c|c|c|c|}
\hline \multirow[b]{2}{*}{$\begin{array}{l}\text { Time } \\
\text { Bin }\end{array}$} & \multirow[b]{2}{*}{$\begin{array}{l}\text { Gamma-Ray } \\
\text { Lines } \\
\end{array}$} & \multicolumn{3}{|c|}{ Intensity Ratio } \\
\hline & & \multirow{2}{*}{$\begin{array}{c}\begin{array}{c}14-\mathrm{MeV} \\
\text { Expt }\end{array} \\
0.052 \pm 0.010\end{array}$} & \multicolumn{2}{|c|}{$\begin{array}{c}\text { 14-MeV } \\
\text { Theory }\end{array}$} \\
\hline \multirow{3}{*}{$1-1.5 \mathrm{~h}$} & \multirow{3}{*}{$\frac{{ }^{132} \mathrm{I}(773)}{{ }^{134} \mathrm{Te}(767)+{ }^{134} \mathrm{I}(767)}$} & & 0.079 & ${ }^{238} \mathrm{U}$ \\
\hline & & $0.14 \pm 0.03$ & 0.484 & ${ }^{235} \mathrm{U}$ \\
\hline & & $0.50 \pm 0.05$ & 1.45 & ${ }^{239} \mathrm{Pu}$ \\
\hline \multirow{3}{*}{$2.5-3.5 \mathrm{~h}$} & \multirow{3}{*}{$\frac{{ }^{132} \mathrm{I}(773)}{{ }^{134} \mathrm{Te}(767)+{ }^{134} \mathrm{I}(767)}$} & $0.25 \pm 0.03$ & 0.315 & ${ }^{238} \mathrm{U}$ \\
\hline & & $0.61 \pm 0.08$ & 1.42 & ${ }^{235} \mathrm{U}$ \\
\hline & & $2.04 \pm 0.10$ & 3.86 & ${ }^{239} \mathrm{Pu}$ \\
\hline \multirow{3}{*}{$5-7 \mathrm{~h}$} & \multirow{3}{*}{$\frac{{ }^{132} \mathrm{I}(773)}{{ }^{134} \mathrm{Te}(767)+{ }^{134} \mathrm{I}(767)}$} & No Data & 3.28 & ${ }^{238} \mathrm{U}$ \\
\hline & & $4.00 \pm 0.69$ & 9.36 & ${ }^{235} \mathrm{U}$ \\
\hline & & $8.55 \pm 0.83$ & 20.4 & ${ }^{239} \mathrm{Pu}$ \\
\hline
\end{tabular}

Following the procedure used for the ${ }^{235} \mathrm{U}-{ }^{239} \mathrm{Pu}$ fission split above, we examined the tabulated data for possible unresolved lines, calculated the decay curves for lines of concern, and identified contributions of more than $5 \%$ of the primary line intensity in each time bin of interest. The only contributions greater than $5 \%$ occur for the ${ }^{132} \mathrm{I}(773)$ line in the $2.5-3.5 \mathrm{~h}$ time bin, for which corrections of $14 \%, 19 \%$, and $9 \%$ were made for ${ }^{238} \mathrm{U},{ }^{235} \mathrm{U}$, and ${ }^{239} \mathrm{Pu}$, respectively. Small adjustments were made to the experimental values for the difference between the actual and nominal time intervals, and for buildup and decay during the irradiation interval. 
Table V. Intensity ratios for ${ }^{132} \mathrm{I}(773) /{ }^{134} \mathrm{I}(847)$. Measured values for $14-\mathrm{MeV}$ neutron fission are compared to the theoretical values for ${ }^{238} \mathrm{U},{ }^{235} \mathrm{U}$, and ${ }^{239} \mathrm{Pu}$.

\begin{tabular}{|c|c|c|c|c|}
\hline \multirow[b]{2}{*}{$\begin{array}{l}\text { Time } \\
\text { Bin }\end{array}$} & \multirow[b]{2}{*}{$\begin{array}{c}\text { Gamma-Ray } \\
\text { Lines }\end{array}$} & \multicolumn{3}{|c|}{ Intensity Ratio } \\
\hline & & \multirow{2}{*}{$\begin{array}{c}\begin{array}{c}14-\mathrm{MeV} \\
\mathrm{Expt}\end{array} \\
0.016 \pm 0.004\end{array}$} & \multicolumn{2}{|c|}{$\begin{array}{l}\text { 14-MeV } \\
\text { Theory }\end{array}$} \\
\hline \multirow{3}{*}{$1-1.5 \mathrm{~h}$} & \multirow{3}{*}{$\frac{{ }^{132} \mathrm{I}(773)}{{ }^{134} \mathrm{I}(847)}$} & & 0.020 & ${ }^{238} \mathrm{U}$ \\
\hline & & $0.037 \pm 0.006$ & 0.086 & ${ }^{235} \mathrm{U}$ \\
\hline & & $0.10 \pm 0.01$ & 0.208 & ${ }^{239} \mathrm{Pu}$ \\
\hline \multirow{3}{*}{$2.5-3.5 \mathrm{~h}$} & \multirow{3}{*}{$\frac{{ }^{132} \mathrm{I}(773)}{{ }^{134} \mathrm{I}(847)}$} & $0.041 \pm 0.003$ & 0.041 & ${ }^{238} \mathrm{U}$ \\
\hline & & $0.069 \pm 0.007$ & 0.152 & ${ }^{235} \mathrm{U}$ \\
\hline & & $0.21 \pm 0.01$ & 0.369 & ${ }^{239} \mathrm{Pu}$ \\
\hline \multirow{3}{*}{$5-7 \mathrm{~h}$} & \multirow{3}{*}{$\frac{{ }^{132} \mathrm{I}(773)}{{ }^{134} \mathrm{I}(847)}$} & No Data & 0.250 & ${ }^{238} \mathrm{U}$ \\
\hline & & $0.45 \pm 0.02$ & 0.655 & ${ }^{235} \mathrm{U}$ \\
\hline & & $0.91 \pm 0.03$ & 1.36 & ${ }^{239} \mathrm{Pu}$ \\
\hline
\end{tabular}

Although our data clearly show a strong dependence of the 668- and 773-keV gamma-ray intensities on fissioning isotope, two inconsistencies with "theory" cast suspicion on the tabulated data and possibly the identification of these peaks. First, the time dependence of the 773-keV peak for ${ }^{235} \mathrm{U}$ does not follow the theoretical curve for the first two hours after fission. Second, the $668-\mathrm{keV}$ peak is actually an incompletely resolved doublet at roughly one hour after fission with no explanation for the other line. We note that, according to the tabulated data, 665- and 774-keV gamma rays are emitted in the decay of ${ }^{131 \mathrm{~m}} \mathrm{Te}$, but their theoretical intensity is too low to explain the inconsistency (The small theoretical contribution of the $774-\mathrm{keV}^{131 \mathrm{~m}} \mathrm{Te}$ line has been removed from the experimental ratios in Tables IV and V as part of the correction for unresolved lines.) 
In addition to their isotope sensitivity, the ${ }^{132}$ I gamma rays also have a strong dependence on neutron energy and are much weaker for fission by low energy neutrons. Hence fission of ${ }^{239} \mathrm{Pu}$ by low energy neutrons and fission of ${ }^{238} \mathrm{U}$ by high energy neutrons both produce weak ${ }^{132}$ I gamma rays, and independent information about the neutron energy distribution is required to distinguish between the two isotopes.

\section{Neutron Energy}

Data tabulations list fission product yields for three neutron energies: thermal, fission-spectrum, and 14-MeV [8]. Fission product distributions for thermal and fissionspectrum neutrons are very similar (see Tables I and VII), and our measurements for thermal neutrons may be taken as applying to fission-spectrum neutrons as well. Much higher neutron energy (e.g., $14 \mathrm{MeV}$ ) dramatically increases the yield of the lowabundance valley and wing fission products. We have identified several gamma-ray lines from isotopes near mass 130 (on the lower wing of the upper mass peak) that provide information on neutron energy. These lines and nearby reference lines are listed in Table VI by time bin and energy band. We did not find prominent lines sensitive to neutron energy in the 5-8 $\mathrm{m}$ time bin, partly because of the limited number of counts in that 3minute counting interval. Since $14-\mathrm{MeV}$ spectra were not recorded for the $10-14 \mathrm{~h}$ time interval, we do not list lines for that time bin. However the longer-lived lines in the 5-7 $\mathrm{h}$ time bin will still be useful at later times.

One spectral region for each of the time bins for which good data were obtained is shown in Fig. 6 for ${ }^{235} \mathrm{U}$ fission. The spectra for ${ }^{239} \mathrm{Pu}$ are similar. To illustrate the changing prominence of different line pairs at different times, the theoretical time dependence of the gamma-ray lines identified in Fig. 6 is plotted in Fig. 7. 
Table VI. Gamma-ray lines that are sensitive to neutron energy. Gamma rays are identified by parent isotope and energy $(\mathrm{keV})$, and are grouped by energy band and time bin. The ratio of the intensity of a gamma ray above the dashed line to that of a gamma ray below the dashed line in each group is much larger for high neutron energy than for low neutron energy.

\begin{tabular}{|c|c|c|c|c|}
\hline \multirow{2}{*}{$\begin{array}{c}\text { Energy } \\
\text { Band } \\
(\mathrm{keV}) \\
\end{array}$} & \multicolumn{4}{|c|}{ Time Bin } \\
\hline & $18-33 \mathrm{~m}$ & $1-1.5 \mathrm{~h}$ & $2.5-3.5 \mathrm{~h}$ & $5-7 \mathrm{~h}$ \\
\hline \multirow{8}{*}{$\begin{array}{c}740 \\
-850\end{array}$} & ${ }^{129 m} \mathrm{Sb}(761)$ & ${ }^{128} \mathrm{Sb}(754)$ & \multirow{2}{*}{$\begin{array}{l}{ }^{128} \mathrm{Sb}(754) \\
{ }^{129} \mathrm{Sb}(813)\end{array}$} & \multirow{2}{*}{$\begin{array}{l}{ }^{128} \mathrm{Sb}(754) \\
{ }^{129} \mathrm{Sb}(813)\end{array}$} \\
\hline & ${ }^{134} \mathrm{Te}(743)$ & ${ }^{134} \mathrm{Te}(743)$ & & \\
\hline & ${ }^{134} \mathrm{Te}(767)$ & ${ }^{97} \operatorname{Zr}(743)$ & ${ }^{134} \mathrm{Te}(743)$ & ${ }^{97} \mathrm{Zr}(743)$ \\
\hline & \multirow[t]{4}{*}{${ }^{134} \mathrm{I}(767)$} & ${ }^{134} \mathrm{Te}(767)$ & ${ }^{97} \operatorname{Zr}(743)$ & \multirow[t]{4}{*}{${ }^{134} \mathrm{I}(847)$} \\
\hline & & ${ }^{134} \mathrm{I}(767)$ & ${ }^{134} \mathrm{Te}(767)$ & \\
\hline & & ${ }^{134} \mathrm{I}(847)$ & ${ }^{134} \mathrm{I}(767)$ & \\
\hline & & & ${ }^{134} \mathrm{I}(847)$ & \\
\hline & & & ${ }^{127} \mathrm{Sn}(1096)$ & ${ }^{127} \mathrm{Sn}(1096)$ \\
\hline \multirow{4}{*}{$\begin{array}{c}1070 \\
-1140\end{array}$} & & & ${ }^{127} \mathrm{Sn}(1114)$ & ${ }^{127} \operatorname{Sn}(1114)$ \\
\hline & & & ${ }^{134} \mathrm{I}(1073)$ & \multirow[t]{3}{*}{${ }^{135} \mathrm{I}(1132)$} \\
\hline & & & ${ }^{135} \mathrm{I}(1132)$ & \\
\hline & & & ${ }^{134} \mathrm{I}(1136)$ & \\
\hline
\end{tabular}



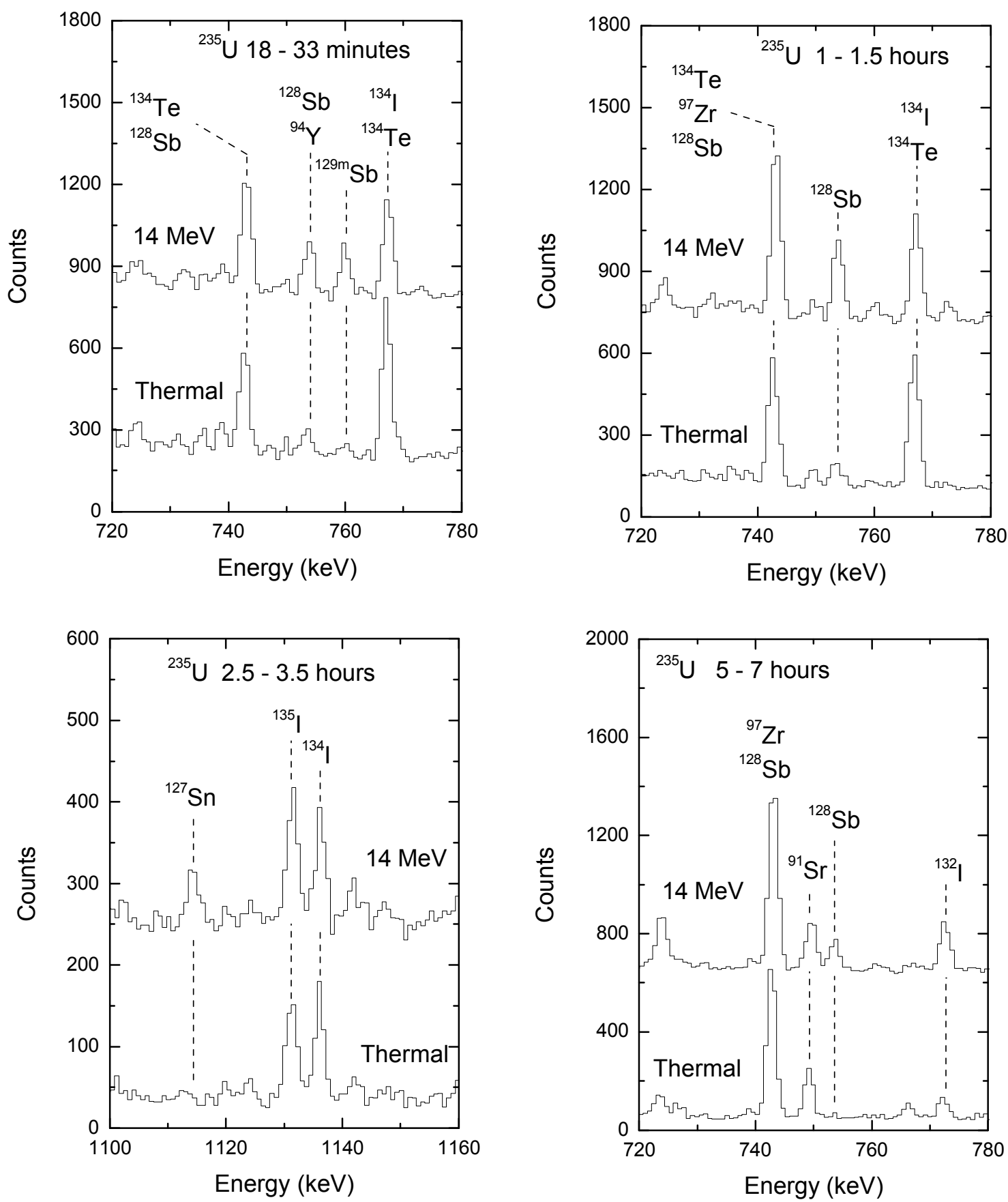

Fig. 6. Spectral regions showing line pairs that are sensitive to neutron energy at different times for ${ }^{235} \mathrm{U}$ fission. The vertical scales apply to the thermal-neutron spectra. The 14-MeV spectra have been multiplied by a scale factor and offset vertically for display purposes. Some peaks include significant unresolved contributions from more than one isotope as indicated by multiple labels. 

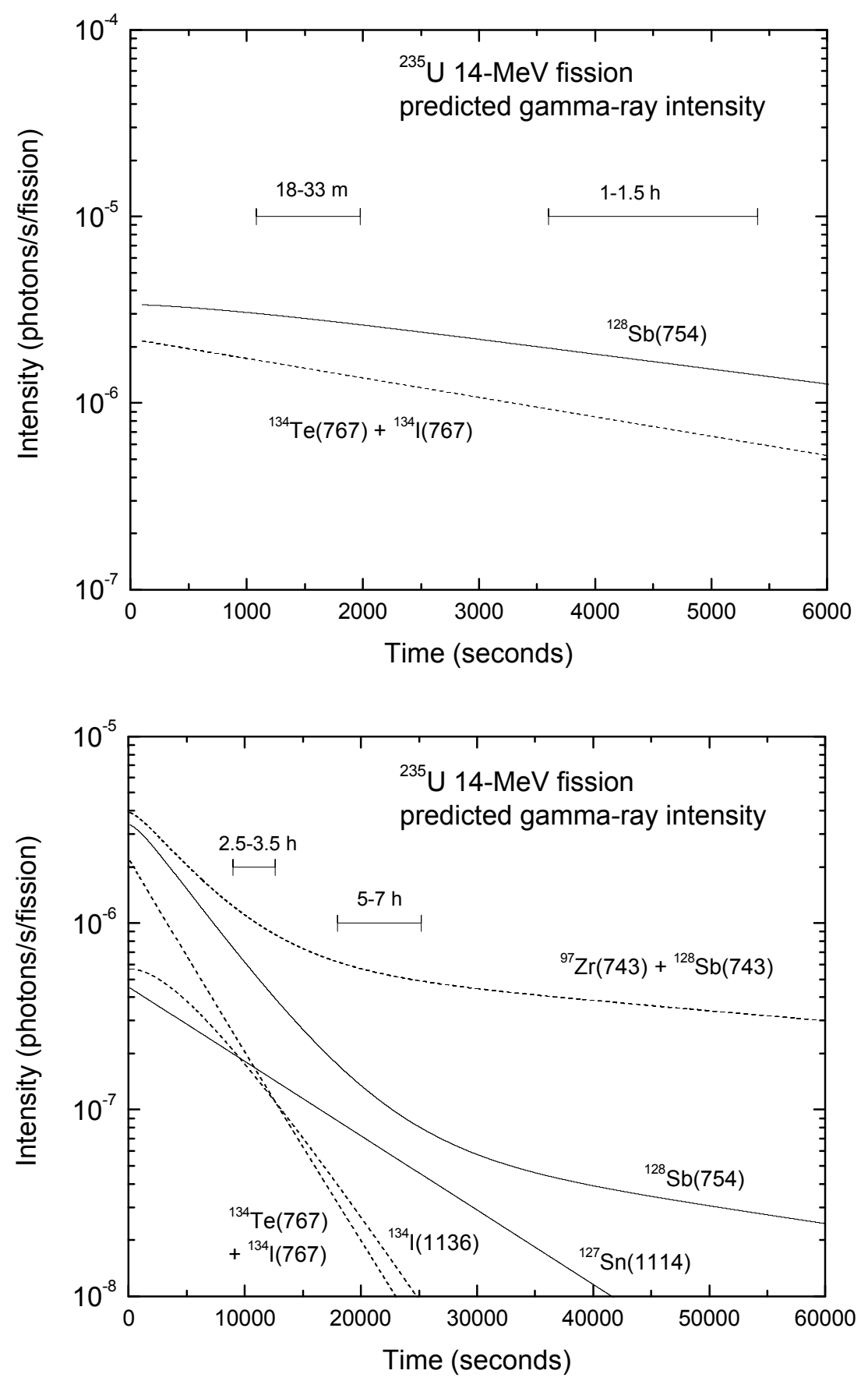

Fig. 7. Theoretical time dependence of the indicated gamma-ray intensities for fission of ${ }^{235} \mathrm{U}$ by $14-\mathrm{MeV}$ neutrons. Intensities of gamma rays that are more intense for fission by 14-MeV neutrons than by low-energy neutrons are shown as solid curves. Intensities of reference gamma rays are shown dashed. Bars indicate the times bins used for integration. Top: early time. Bottom: late time. The ${ }^{128} \mathrm{Sb}(754)$ and ${ }^{128} \mathrm{Sb}(743)$ curves include contributions from both the ground an metastable states in ${ }^{128} \mathrm{Sb}$. 
Measured and theoretical values for some of the neutron-energy-sensitive line ratios are listed in Table VII. The fission-product yield for ${ }^{129 \mathrm{~m}} \mathrm{Sb}$ is not known, so there are no "theory" values for the intensity of the $761-\mathrm{keV}$ line emitted during its beta decay. The decay of ${ }^{129 \mathrm{~m}} \mathrm{Sn}$ also produces a $761-\mathrm{keV}$ gamma ray, but its theoretical intensity is 10-fold lower than the observed intensity of the 761-keV peak. The observed time dependence of the $761-\mathrm{keV}$ peak is consistent with the $17.7-\mathrm{m}$ half life of ${ }^{129 \mathrm{~m}} \mathrm{Sb}$ (the half life of ${ }^{129 \mathrm{~m}} \mathrm{Sn}$ is $6.9 \mathrm{~m}$ ). Hence we conclude that the contribution of ${ }^{129 \mathrm{~m}} \mathrm{Sn}$ or other unidentified lines to the $761-\mathrm{keV}$ peak is not significant.

Both the ground and metastable states of ${ }^{128} \mathrm{Sb}$ (with half lives of $9.0 \mathrm{~h}$ and 10.4 $\mathrm{m}$, respectively) decay with the emission of a 754-keV gamma ray. During fission, these states are populated primarily through decay of precursor fission products, and their relative population is unknown. We calculated theoretical 754-keV gamma-ray intensities for the two extreme cases of $100 \%$ feeding of either the ground or metastable states of ${ }^{128} \mathrm{Sb}$ in ${ }^{128} \mathrm{Sn}$ beta decay. Feeding of the metastable rather than the ground state is much more consistent with the observed $754-\mathrm{keV}$ peak intensity and decay rate, and that option was used for the theoretical line ratios in Table VII and the decay curves plotted in Fig. 7. We calculated the theoretical intensity of the ${ }^{127} \mathrm{Sn} 1114-\mathrm{keV}$ line with the assumption that decay of the ${ }^{127}$ In precursor feeds the ground state but not the metastable state of ${ }^{127} \mathrm{Sn}$ (decay of ${ }^{127 \mathrm{~m}} \mathrm{Sn}$ does not produce a $1114-\mathrm{keV}$ gamma ray), and that the decay of the ${ }^{127}$ In metastable feeds the metastable but not the ground state of ${ }^{127} \mathrm{Sn}$. (Note that, as listed in the data base [8], the combined independent yields of the ${ }^{127}$ In ground and metastable states is less than half that of the independent yield of the ${ }^{127} \mathrm{Sn}$ ground state for all cases in Table VII.)

Corrections for unresolved lines and time interval variations were made to the measured line intensities using the same procedure as for the isotope-sensitive lines. The largest correction for unresolved lines is $13 \%$. The reference (denominator) lines at 743 and $767 \mathrm{keV}$ each contain significant unresolved contributions from two isotopes as listed in Table VII, and the sum of these contributions was taken as the reference. 
Table VII. Gamma-ray intensity ratios for detecting fission by high energy neutrons. Measured values for both thermal and 14-MeV neutron fission are compared to the theoretical values. Values for ${ }^{235} \mathrm{U}$ and ${ }^{239} \mathrm{Pu}$ are shown in the first and second rows, respectively, in each time bin. The ${ }^{128} \mathrm{Sb}(754)$ and ${ }^{128} \mathrm{Sb}(743)$ lines include contributions from decay of both the ground and metastable states of ${ }^{128} \mathrm{Sb}$.

\begin{tabular}{|c|c|c|c|c|c|c|c|}
\hline \multirow{3}{*}{$\begin{array}{c}\begin{array}{c}\text { Time } \\
\text { Bin }\end{array} \\
18-33 \mathrm{~m}\end{array}$} & \multirow{3}{*}{$\begin{array}{c}\begin{array}{c}\text { Gamma-Ray } \\
\text { Lines }\end{array} \\
\frac{{ }^{129 \mathrm{~m}} \mathrm{Sb}(761)}{{ }^{134} \mathrm{Te}(767)+{ }^{134} \mathrm{I}(767)}\end{array}$} & \multicolumn{6}{|c|}{ Intensity Ratio } \\
\hline & & \multirow{2}{*}{$\begin{array}{c}\begin{array}{c}\text { Thermal } \\
\text { Expt }\end{array} \\
0.12 \pm 0.03 \\
0.25 \pm 0.03\end{array}$} & \multirow{2}{*}{$\begin{array}{c}\text { Thermal } \\
\text { Theory } \\
\text { No } \\
\text { Theory }\end{array}$} & \multirow{2}{*}{$\begin{array}{c}\begin{array}{c}\text { Fission } \\
\text { Spectrum } \\
\text { Theory }\end{array} \\
\text { No } \\
\text { Theory }\end{array}$} & \multirow{2}{*}{$\begin{array}{c}\begin{array}{c}14-\mathrm{MeV} \\
\text { Expt }\end{array} \\
0.51 \pm 0.05 \\
0.89 \pm 0.05\end{array}$} & \multicolumn{2}{|c|}{$\begin{array}{c}\text { 14-MeV } \\
\text { Theory }\end{array}$} \\
\hline & & & & & & $\begin{array}{c}\text { No } \\
\text { Theory }\end{array}$ & ${ }^{239} \mathrm{U}$ \\
\hline $1-1.5 \mathrm{~h}$ & $\frac{{ }^{128} \mathrm{Sb}(754)}{{ }^{134} \mathrm{Te}(767)+{ }^{134} \mathrm{I}(767)}$ & $\begin{array}{l}0.19 \pm 0.03 \\
0.46 \pm 0.03\end{array}$ & $\begin{array}{l}0.160 \\
0.418\end{array}$ & $\begin{array}{l}0.252 \\
0.537\end{array}$ & $\begin{array}{l}0.73 \pm 0.05 \\
1.14 \pm 0.05\end{array}$ & $\begin{array}{l}2.22 \\
2.48\end{array}$ & $\begin{array}{l}{ }^{235} \mathrm{U} \\
{ }^{239} \mathrm{Pu}\end{array}$ \\
\hline $2.5-3.5 \mathrm{~h}$ & $\frac{{ }^{127} \mathrm{Sn}(1114)}{{ }^{134} \mathrm{I}(1136)}$ & $0.17 \pm 0.04$ & 0.175 & 0.094 & $\begin{array}{l}0.64 \pm 0.10 \\
1.73 \pm 0.12\end{array}$ & 1.12 & ${ }^{235} \mathrm{U}$ \\
\hline $5-7 \mathrm{~h}$ & $\frac{{ }^{128} \mathrm{Sb}(754)}{{ }^{97} \mathrm{Zr}(743)+{ }^{128} \mathrm{Sb}(743)}$ & $\begin{array}{l}0.01 \pm 0.01 \\
0.07 \pm 0.01\end{array}$ & $\begin{array}{l}0.027 \\
0.065\end{array}$ & 0.036 & $\begin{array}{l}0.17 \pm 0.02 \\
0.24 \pm 0.01\end{array}$ & $\begin{array}{l}0.215 \\
0.278\end{array}$ & ${ }^{235} \mathrm{U}$ \\
\hline
\end{tabular}

Unlike the gamma-ray lines selected for identifying fissile material, most of the lines we have identified as sensitive to neutron energy have extreme variations in intensity between low and high neutron energy (see Fig. 6). Hence, these gamma rays can reveal a small fraction of high-energy-neutron fission in the presence of a large fraction of low-energy-neutron fission.

Although the theoretical gamma-ray intensity ratios also show an extreme variation between thermal and $14-\mathrm{MeV}$ neutron energy, they differ significantly from the measured ratios in several cases. Because of the strong and nonlinear variation of the intensity of the energy-sensitive lines with neutron energy, the large spread in neutron 
energy in our "14-MeV" measurements may contribute to the difference. In addition, the data tabulations are missing some of the information required for calculation of the theoretical intensities (see discussion of ${ }^{128} \mathrm{Sb}$ and ${ }^{129 \mathrm{~m}} \mathrm{Sb}$ above), and may contain unknown errors and uncertainties, particularly for the weaker lines.

\section{Conclusions}

We have used measurements of the gamma-ray spectra from unseparated fission products to identify line pairs that are suitable for distinguishing between ${ }^{235} \mathrm{U},{ }^{238} \mathrm{U}$, and ${ }^{239} \mathrm{Pu}$ fission. We have also identified line pairs that distinguish between fission induced by low-energy and high-energy neutrons. At least some members of the suite of line pairs are prominent in the gamma-ray spectra at all times from a few minutes to many hours after fission, demonstrating that spectra acquired anywhere within this time range can provide information on the fission process. The diagnostic value of these line pairs will clearly extend beyond the latest measurement times in the present work. In particular, the ${ }^{91} \operatorname{Sr}(1024) /{ }^{135} \mathrm{I}(1039)$ intensity ratio, which distinguishes between ${ }^{235} \mathrm{U}$ and ${ }^{239} \mathrm{Pu}$ fission, will be useful well beyond the 14-hour limit of the present measurements because of the similar lifetimes and persistence of these gamma rays.

Most of our measured gamma-ray intensity ratios agree with expectations based on tabulated fission product yields, half lives, and decay branching ratios. The main exceptions are one line (from ${ }^{129 \mathrm{~m}} \mathrm{Sb}$ ) for which the fission product yield is not known and two lines (from ${ }^{128} \mathrm{Sb}$ and ${ }^{127} \mathrm{Sn}$ ) for which the unknown relative feeding of metastable and ground states had to be inferred from our measurements. The poor agreement of some of our measured line ratios with theory at $14-\mathrm{MeV}$ neutron energy might arise from the broad neutron energy distribution used in the measurements, as well as from errors and uncertainties in the tabulated data.

Two features of the present set of gamma-ray line pairs will be important if gamma-ray spectra are obtained from an unexpected fission event. First, the small difference in energy of the gamma-rays in each pair reduces corrections for variation in 
detector efficiency and differential absorption in intervening material. Second, all of the gamma-ray lines originate from fission product mass chains of similar volatility so that chemical fractionation of the parent isotopes and their precursors is small compared to that of isotopes of dissimilar volatility.

\section{Acknowledgements}

The authors thank L. A. Bernstein for helpful discussions. This work performed under the auspices of the U. S. Department of Energy by Lawrence Livermore National Laboratory under Contract DE-AC52-07NA27344.

\section{References}

[1] E. B. Norman et al., Nucl. Instr. and Meth. A 521, 608 (2004).

[2] D. H. Beddingfield and F. E. Cecil, Nucl. Instr. and Meth. A 417, 405 (1998).

[3] C. L. Hollas, D. A. Close, and C. E. Moss, Nucl. Instr. and Meth. B 24, 503 (1987).

[4] J. P. Meulders, P. Leleux, P. C. Macq, and C. Pirart, Phys. Med. Biol. 20, 235 (1975).

[5] A. Belyman, A. Hoummada, J. Collot, P. de Saintignon, G. Mahout, and B. Merkel, Nucl. Instr. and Meth. B 134, 217 (1998).

[6] M. A. Lone, A. J. Ferguson, and B. C. Robertson, Nucl. Instr. and Meth. 189, 515 (1981).

[7] R. B. Firestone and L. P. Ekstrom, Table of Radioactive Isotopes, 2004, $<$ http://ie.lbl.gov/toi/>.

[8] T. R. England and B. F. Rider, Los Alamos National Laboratory Report LA-UR-943106 (1994). 